\title{
Erratum to: Viable Stabilising Non-Taylor Monetary Policies for an Open Economy
}

\author{
Jacek B. Krawczyk • Kunhong Kim
}

Published online: 23 October 2013

(C) Springer Science+Business Media New York 2013

\section{Erratum to: Comput Econ DOI 10.1007/s10614-013-9360-4}

Unfortunately in the original publication, the year of reference in the abstract for Krawczyk and Kim (Macroecon Dyn 13(1):46-80, 1999) has been incorrectly stated. The correct publication year should be 2009 .

The corrected penultimate sentence in the abstract should read as "We also discuss the robustness of such policies to shocks and parameter uncertainty and observe that viability-based policies come from models, which do not require explicit weights on the variables of interest of a central bank."

The online version of the original article can be found under doi:10.1007/s10614-013-9360-4.

J. B. Krawczyk $(\bowtie)$

Victoria University of Wellington, Wellington, New Zealand e-mail: J.Krawczyk@vuw.ac.nz

K. Kim

Hallym University, Chuncheon, Republic of Korea

e-mail: kimku@hallym.ac.kr 